\title{
EPILEPSI POST TRAUMA DENGAN GEJALA PSIKOTIK
}

\author{
Laily Irfana \\ Departemen Neurologi, Fakultas Kedokteran, Universitas Muhammadiyah Surabaya \\ e-mail: : irfanalaily@gmail.com
}

\begin{abstract}
Abstrak: Data WHO menunjukkan epilepsi menyerang 1\% penduduk dunia. Angka kejadian epilepsi masih tinggi terutama di negara berkembang yaitu mencapai 114 per 100.000 penduduk per tahun. ${ }^{2}$ Pada kelompok dewasa muda, epilepsi dapat terjadi salah satunya disebabkan oleh trauma kepala. ${ }^{3}$ Kasus ini melaporkan penderita laki-laki usia 24 tahun dengan keluhan kejang yang disertai dengan gejala psikotik. Didapatkan riwayat pasien kejang pertama kali dua bulan setelah mengalami trauma kepala yaitu pada tahun 2003. Saat itu pasien mengalami cedera otak berat dan dari CT scan kepala didapatkan perdarahan di otak. Dua bulan setelah trauma kepala itu pasien mengalami kejang berulang disertai keluhan yang dominan adalah marah-marah hingga pernah sampai mau membunuh orang. Dari analisis EEG menunjukkan hasil epilepsi lobus frontotemporal. Setelah pasien mendapatkan pengobatan phenytoin dan risperidone, kejang mulai terkontrol. Namun bila tidak minum obat pasien kejang lagi. Hal ini dialami oleh pasien hingga saat kasus ini dilaporkan, yaitu sepuluh tahun post trauma.
\end{abstract}

Kata kunci: Epilepsi Post Trauma, psychotic epilepsy

\section{PENDAHULUAN}

Epilepsi merupakan salah satu penyakit neurologis yang sering ditemukan. Data WHO menunjukkan epilepsi menyerang $1 \%$ penduduk dunia. Epilepsi dapat terjadi pada siapa saja di seluruh dunia tanpa batasan ras dan sosial ekonomi. Angka kejadian epilepsi masih tinggi terutama di negara berkembang yaitu mencapai 114 per 100.000 penduduk per tahun. Prevalensi epilepsi pada bayi dan anak-anak cukup tinggi, menurun pada dewasa muda dan pertengahan, kemudian meningkat lagi pada kelompok usia lanjut yang disebabkan oleh penyakit serebrovaskuler. $^{2}$ Pada kelompok dewasa muda, epilepsi dapat terjadi akibat trauma, neoplasma, gangguan vaskuler, maupun penggunaan alkohol dan obat-obat sedatif lain. ${ }^{3}$

Epilepsi secara garis besar dapat digolongkan menjadi epilepsi idiopatik, kriptogenik, dan simtomatik. Epilepsi pasca trauma termasuk dalam epilepsi simtomatik. Merupakan sekuel dari trauma kepala yang paling sering terjadi, dengan insiden $5 \%$ pada penderita dengan trauma kepala tertutup dan $50 \%$ pada penderita dengan fraktur tulang tengkorak dan jejas pada otak. ${ }^{4}$ Tipe kejang pada eplepsi pasca trauma dapat berbeda-beda bergantung pada lesi yang diakibatkan oleh trauma tersebut.

\section{TINJAUAN PUSTAKA}

\section{Definisi Epilepsi}

Epilepsi adalah suatu keadaan yang ditandai oleh bangkitan epilepsi berulang berselang lebih dari 24 jam yang timbul tanpa provokasi. Yang dimaksud dengan bangkitan epilepsi adalah manifestasi klinik yang disebabkan oleh aktivitas listrik otak yang abnormal dan berlebihan dari sekelompok neuron. Manifestasi klinik ini terjadi secara tiba-tiba dan sementara berupa perubahan perilaku yang stereotipik, dapat menimbulkan gangguan kesadaran, gangguan motorik, sensorik, otonom, ataupun psikik. ${ }^{1}$

\section{Etiologi Epilepsi}

Etiologi epilepsi dapat dibagi ke dalam 3 kategori, yaitu: 
1. Idiopatik: tidak terdapat lesi struktural di otak atau defisit neurologik. Diperkirakan mempunyai predisposisi genetik dan umumnya berhubungan dengan usia.

2. Kriptogenik: dianggap simtomatik tetapi penyebabnya belum diketahui. Gambaran klinik sesuai dengan ensefalopati difus

3. Simtomatik : bangkitan epilepsi disebabkan oleh kelainan/lesi struktural pada otak, misalnya cedera kepala, infeksi SSP, kelainan kongenital, lesi desak ruang, gangguan peredaran darah otak, toksik (alkohol, obat), metabolik, kelainan degeneratif. ${ }^{1}$

\section{Klasifikasi}

Klasifikasi yang ditetapkan oleh International League Against Epilepsy (ILAE) terdiri dari 2 jenis klasifikasi, yaitu klasifikasi untuk jenis bangkitan epilepsi (ILAE 1981), dan klasifikasi untuk sindrom epilepsi (ILAE 1989). Pada bangkitan umum, manifestasi klinis dan EEG mengindikasikan adanya keterlibatan korteks serebri bilateral dan difus pada awal onset. Pada bangkitan fokal, manifestasi klinis merupakan manifestasi dari lesi fokal yang tampak pada abnormalitas EEG. ${ }^{1}$ Hemisferium serebri dibagi menjadi lobus frontalis, lobus parietalis, lobus okipitalis, lobus temporalis. Berbagai penelitian menyebutkan bahwa psikotik epilepsi merupakan lesi yang terjadi pada lobus temporalis dan lobus frontalis. ${ }^{4}$

Lobus temporalis berfungsi untuk memproses input auditori, mengenali objek visual, ditambah dengan fungsi amigdala, yaitu afeksi (emosi) pada input sensori dan memori.

Pada lobus temporalis terdapat daerah fungsional sebagai berikut: ${ }^{4}$

\section{a. Korteks area auditorus primer}

Merupakan area Brodman 41 dan 42, terdapat dalam insula (girus Heschl). Korniokorteks area pendengaran ini menerima impuls pendengaran dari korpus genikulatum mediale melalui radiasio akustik yang berjalan melalui pars sublentikularis krus posterior kapsula interna.

Pada hemisfer dominan, girus temporalis superior pars posterior (area 22) dan girus angular (area 39) penting untuk fungsi pendengaran bahasa bicara dan tulisan. Sedangkan hemisfer nondominan berperan dalam pendengaran suara, irama dan musik. $(8,12)$

\section{b. Korteks area olfaktorik primer}

Bagian anterior uncus merupakan bagian korteks area olafktorik primer terpenting. Daerah yang lain meliputi kroteks prepiriformis (anterior 28) dan substansia perforata anterior. Rhinensefalon dalam arti lebih terbatas meliputi bagian susunan saraf yang menerima serat-serat dari bulbus olfaktorius sehingga mencakup traktus olfaktorius, striae olfaktorius bagian tertentu korpus amygdaloid, uncus, korteks prepiriformis dan substansia perforata anterior.

\section{c. Visual pathways}

Area visual ekstratriata melintas disebelah dalam dari lobus temporalis sekitar krus posterior ventrikel lateralis.

\section{d. Girus temporalis inferior dan medial.}

Berperan dalam kegiatan belajar dan memori. Seperti diketahui belajar adalah suatu proses untuk mendapatkan pengetahuan tentang dunia yang dipengaruhi oleh pengalaman, sedangkan memori adalah simpanan informasi yang dapat dipanggil kembali. ${ }^{4}$

\section{Kejang Parsial Kompleks (Kejang Psikomotor, Kejang Lobus Temporal)}

Karakteristik dari bangkitan tipe ini adalah adanya:

1. Aura, terdapat pada awal bangkitan, dapat berupa halusinasi, ilusi.

2. Hilangnya kontrol pikiran dan tindakan, terdapat periode perubahan perilaku dan kesadaran, yang setelahnya penderita mengalami amnesia. ${ }^{3}$ 
Halusinasi pada penderita bangkitan tipe ini pada umumnya adalah halusinasi visual dan auditorik, terdiri dari gambaran visual yang jelas maupun tidak, suara-suara, gangguan pengecapan, vertigo, dan yang paling jarang adalah halusinasi bau. Terdapat juga gejala diskognitif berupa déjà $v u$, jamais $v u$, atau rasa depersonalisasi. Gejala emosional berupa sedih, kesepian, marah, gembira, takut, dan cemas juga didapatkan. ${ }^{3}$

Gejala motorik juga dapat terjadi, seperti mengecap, mengunyah, salivasi, menggoyanggoyangkan kaki. Penderita juga dapat berperilaku tidak pantas seperti telanjang di depan umum atau meracau. Saat terjadi bangkitan, penderita kehilangan kontak terhadap sekitarnya. Tidak jarang juga penderita yang perilakunya menjadi agresif dan melakukan kekerasan. Lennox menyebutkan perubahan motorik, perilaku automatisme, dan perubahan fungsi psikis sebagai trias psikomotor. ${ }^{3}$

Kejang parsial kompleks erat kaitannya dengan gangguan kepribadian, perilaku, dan psikiatrik. Penelitian oleh Vitoroff menyebutkan bahwa sepertiga dari penderita memiliki riwayat penyakit depresif mayor dan dengan jumlah yang sama memiliki gejala gangguan kecemasan. Gejala psikotik ditemukan pada $10 \%$ kasus. Fase pascaiktal pada penderita epilepsi lobus temporal kadang berupa gejala delusional-paranoid atau psikotik amnestik yang dapat berlangsung beberapa hari hingga berminggu-minggu. Perekaman EEG pada periode ini mungkin tidak menunjukkan aktivitas kejang meski tidak menyingkirkan adanya kemungkinan aktivitas kejang pada amigdala dan struktur lobus temporal yang lebih dalam. Gangguan yang sulit dibedakan dengan skizofrenia ini dapat ditemukan pada periode interiktal. ${ }^{3}$

\section{Klasifikasi Psikotik Epilepsi}

Berdasarkan ada atau tidaknya bangkitan, psikosis epilepsi terbagi dalam :

\section{Psikosis iktal}

Khas timbul pada status epileptikus nonkonvulsif, termasuk status parsial sederhana, status parsial kompleks, dan status absans. Perubahan perilaku pada psikotik iktal hampir selalu paroksismal dan menjadi gejala puncak kejang. Psikotik iktal terjadi selama status epileptikus non konvulsif, yaitu suatu kondisi di mana aktivitas epileptik memanjang, tanpa kejang, dapat menyebabkan perubahan status mental menjadi tahap psikotik dengan adanya halusinasi dan delusi, gangguan kognitif (gangguan perhatian, kesulitan dalam melakukan perintah motorik kompleks, gangguan berbicara), dan perilaku bizarre.

\section{Psikosis post-iktal}

Fenomena psikotik postiktal dapat berupa gejala terisolasi atau sebagai sekelompok gejala yang menyerupai gangguan psikotik. Gejala psikotik yang menonjol bersifat pleomorfik (persecutory, waham kebesaran, referential, somatik, waham keagamaan, katatonik, halusinasi), dengan gejala afektif (manik atau depresi).

Kriteria psikotik postiktal menurut Stagno (1997), adalah sbb:

$\checkmark$ Gejala psikotik atau psikiatrik lainnya terjadi setelah bangkitan, atau yang sering terjadi pada serial kejang, setelah lucid interval, atau dalam waktu 7 hari setelah kejang.

$\checkmark$ Adanya psikotik, depresi atau elasi, atau gejala yang berhubungan dengan anxietas.

$\checkmark$ Adanya pembatasan waktu, dalam beberapa hari atau minggu, tidak signifikan jika terdapat kesadaran berkabut (bukan karena toksikasi obat, status epileptikus parsial kompleks, atau gangguan metabolik).

Temuan serupa dari beberapa penelitian serial kasus psikotik epilepsi adalah : 1) 
keterlambatan antara onset gejala psikiatrik dan waktu kejang terakhir; 2) waktu durasi relatif pendek; 3) affect-laden symptomatology; 4) sekelompok gejala delusi dan psikotik seperti gangguan afektif; 5) meningkatnya frekuensi bangkitan tonik klonik umum sekunder pada onset psikotik epilepsi; 6) onset psikotik epilepsi timbul setelah kejang lebih dari 10 tahun; dan 7) respon cepat dengan terapi neuroleptik atau benzodiazepin dosis rendah.

\section{Psikosis inter-iktal}

Fenomena psikotik interiktal, khususnya halusinasi dan delusi, sering terjadi pada pasien epilepsi. Tarulli et al (2001) melaporkan beberapa kasus pasien dengan episode multipel psikotik postiktal sebelum berkembang menjadi psikotik interiktal. Sehingga perlu penatalaksanaan psikotik postiktal yang tepat untuk mencegah dan menghambat perkembangannya menjadi psikotik interiktal.

Psikotik pada epilepsi interiktal telah diidentifikasi khas terjadi pada pasien dengan epilepsi parsial. Telah terjadi perdebatan yang luas mengenai kemungkinan bahwa psikotik pada epilepsi adalah indikasi TLE (temporal lobe epilepsy). Sementara penelitian lainnya menunjukkan bahwa proporsi TLE antara pasien psikotik pada epilepsi tidak lebih tinggi dibandingkan pada populasi umum. . $^{2,3,6,7,8}$

Tabel 1. Klasifikasi psikotik epilepsi

\begin{tabular}{|c|c|c|c|c|}
\hline $\begin{array}{c}\text { Tipe } \\
\text { psikotik }\end{array}$ & $\begin{array}{c}\text { Hubungan } \\
\text { dengan } \\
\text { bangkitan }\end{array}$ & Durasi & EEG & Terapi \\
\hline $\begin{array}{l}\text { Psikotik } \\
\text { iktal }\end{array}$ & $\begin{array}{l}\text { Selama status } \\
\text { epileptikus }\end{array}$ & $\begin{array}{c}\text { Beberapa } \\
\text { menit s/d jam }\end{array}$ & $\begin{array}{c}\text { Iktal (status non } \\
\text { konvulsif) }\end{array}$ & $\begin{array}{c}\text { Benzodiazepin, } \\
\text { antiepileptik }\end{array}$ \\
\hline $\begin{array}{l}\text { Psikotik } \\
\text { Postiktal }\end{array}$ & $\begin{array}{l}\text { Saat bingung } \\
\text { setelah } \\
\text { bangkitan dan } \\
\text { lucid interval }\end{array}$ & $\begin{array}{l}\text { Beberapa hari } \\
\text { s/d minggu }\end{array}$ & $\begin{array}{c}\text { Perlambatan } \\
\text { postiktal }\end{array}$ & $\begin{array}{l}\text { Benzodiazepin, } \\
\text { antipsikotik }\end{array}$ \\
\hline $\begin{array}{l}\text { Psikotik } \\
\text { alternatif }\end{array}$ & $\begin{array}{c}\text { Ketika kejang } \\
\text { berkurang atau } \\
\text { disupresi }\end{array}$ & $\begin{array}{c}\text { Beberapa } \\
\text { minggu s/d } \\
\text { bulan }\end{array}$ & $\begin{array}{c}\text { Lebih baik atau } \\
\text { normal }\end{array}$ & $\begin{array}{l}\text { Antipsikotik, } \\
\text { antiepileptik }\end{array}$ \\
\hline $\begin{array}{l}\text { Psikotik } \\
\text { seperti } \\
\text { skizopreni } \\
\text { a kronis }\end{array}$ & $\begin{array}{c}\text { Tidak ada } \\
\text { hubungan } \\
\text { spesifik dengan } \\
\text { kejang }\end{array}$ & Beberapa tahun & $\begin{array}{c}\text { Sebagian besar } \\
\text { abnormal }\end{array}$ & Antipsikotik \\
\hline
\end{tabular}

\section{Epilepsi Pascatrauma}

Epilepsi merupakan sekuel yang paling sering terjadi setelah terjadi trauma kranioserebral. Penyebabnya adalah benturan atau laserasi pada korteks serebri. Risiko terjadinya epilepsi pascatrauma berhubungan dengan beratnya trauma kepala. Sebuah penelitian yang dilakukan Annegers terhadap 2747 penderita trauma kepala, 
risiko terjadinya kejang setelah cedera kepala berat (penurunan kesadaran atau amnesia lebih dari 24 jam), termasuk perdarahan subdural dan gegar otak) adalah 7\% dalam jangka waktu 1 tahun dan $11,5 \%$ dalam 5 tahun. Jika cedera kepala sedang (penurunan kesadaran atau amnesia selama 30 menit sampai 24 jam, atau hanya menyebabkan fraktur tulang tengkorak), risiko berkurang menjadi $0,7 \%$ dan $1,6 \%$. Pada cedera kepala ringan (penurunan kesadaran atau amnesia kurang dari 30 menit), risiko terjadi kejang tidak lebih besar daripada populasi umum. Risiko terjadinya epilepsi lebih besar jika trauma terjadi pada daerah parietal dan frontal posterior, serta setelah trauma kepala tajam. ${ }^{4}$

Interval antara trauma kepala dan terjadinya kejang pertama bervariasi. Sebagian kecil penderita mengalami kejang beberapa saat setelah trauma (immediate epilepsy). 4-5\% penderita trauma kepala mengalami kejang pertama dalam minggu pertama (early epilepsy). Epilepsi pascatrauma sendiri sebenarnya merujuk pada late epilepsy, yaitu kejang yang terjadi beberapa minggu atau bulan setelah trauma (1 sampai 3 bulan). Sekitar 6 bulan pascatrauma, 50\% penderita mengalami kejang pertama. Pada 2 tahun pascatrauma, kemungkinannya meningkat menjadi $80 \%{ }^{4}$

\section{LAPORAN KASUS}

\section{Identitas Pasien}

Nama : Sdr.AZ
Umur : 24 Tahun
Jenis Kelamin : Laki-laki
Tanggal Pemeriksaan : 20 Mei 2013

\section{Riwayat Penyakit Sekarang}

Keluhan Utama : Kejang

Autoanamnesis dan heteroanamnesis:

Kejang terjadi sejak 3 hari sebelum MRS. Saat kejang seluruh lengan dan tungkai menghentak-hentak. Mata melirik ke atas. Mulut berbusa + , lidah tergigit + , ngompol+. Lama kejang sekitar 5 menit. Setelah kejang pasien tertidur. Kejang terjadi $>5 \mathrm{x}$ dalam sehari. Diantara kejang pasien sadar. Kejang seringkali diawali dengan marah-marah, mengamuk, sampai-sampai pasien mencekik ibunya. Setelah itu pasien tidak sadar dengan apa yang dia lakukan.

Pasien mengalami kejang pertama kali sekitar sepuluh tahun y.l. Saat kejang seluruh lengan dan tungkai menghentak-hentak. Mata melirik ke atas. Mulut berbusa + , lidah tergigit + , ngompol+. Lama kejang sekitar 5 menit. Sebelum kejang pasien sering marah-marah, namun bila ditanya setelah kejang berhenti pasien mengatakan lupa. Setelah kejang pasien tertidur. Kejang mulai terjadi 2 bulan setelah pasien mengalami kecelakaan motor. Pasien mengalami benturan kepala, muntah-muntah, kemudian tidak sadar. Dilakukan pemeriksaan CT scan Kepala didapatkan perdarahan otak, kemudian diopnamekan di RS Sidoarjo selama dua minggu. Tidak dilakukan tindakan operasi. Pasien pulang tanpa gejala sisa, namun dua bulan kemudian pasien mulai sering mengalami kejang, hingga $2 x /$ bulan dengan bentuk kejang yang sama. Pasien dibawa keluarganya berobat ke puskesmas dan mendapatkan obat yang diminum tiga kali sehari, ibu pasien lupa nama obatnya. Tidak minum obat teratur dan tidak kontrol lagi. Kejang tetap terjadi sekitar 1 bulan sekali.

Dua tahun setelah kejang pertama, selain bentuk kejang sebelumnya, terkadang pasien juga sering tiba-tiba mengecap-ngecap, kemudian berjalan mondar mandir, dan pasien tidak menyadari apa yang dilakukannya.

Empat tahun ini pasien sering marah-marah, berteriak-teriak, pernah hingga menusuk-nusuk badannya. Tiga tahun setelah keluhan tersebut baru dibawa berobat ke RSJ Lawang dan opname selama 2 bulan. Setelah itu pasien membaik, namun tidak rutin kontrol.

Dua minggu sebelum MRS, pasien semakin sering marah-marah dan memukuli orang hingga 
akhirnya pasien dipasung dan diborgol oleh warga.

Selama itu pasien semakin sering kejang hingga oleh perangkat desa dibawa ke RSDS.

Riwayat nyeri kepala kronis (-), muntah (-), kejang (-), kelemahan sepruh badan (-), kesemutan/tebal (-), bicara pelo (-), merot (-), gangguan penglihatan (-), gangguan pendengaran $(-)$, gangguan BAB dan BAK (-).

\section{Riwayat Penyakit Dahulu}

- Tahun 2003, riwayat trauma kepala pingsan, muntah, luka jahitan di kepala samping kanan. CT scan kepala didapatkan perdarahan di otak.

Kemudian dirawat selama 2 minggu di RS Sidoarjo.

- Tahun 2009, opname di RS Jiwa Lawang selama 2 minggu, karena marah-marah.

- Tahun 2011, opname di RS Jiwa Kalimantan Selatan selama 1,5 tahun, karena marah-marah dan membunuh orang.

- Keluarga pasien tidak ada yang sakit seperti pasien.

- Riwayat kehamilan: dalam batas normal, tidak mengkonsumsi jamu-jamu atau obat-obatan tertentu.

- Riwayat kelahiran : lahir terlambat bulan, normal, ditolong bidan.

Saat lahir sempat biru, langsung menangis.

Kejang demam sejak umur 9 bulan hingga 4 tahun.

- Riwayat tumbuh kembang : sesuai anak pada umurnya.

- Riwayat pendidikan : Tamat SD, dengan prestasi biasa. Tidak melanjutkan sekolah sejak pasien sering kejang setelah kecelakaan.

\section{Pemeriksaan Fisik}

Status Internistik

Kesadaran : Composmentis
Tekanan Darah: 140/90 mmHg; Nadi: 82 x/menit; RR:18x/menit; Temperatur Aksila: 36,5 celcius Status generalis dbn

\section{Status Neurologis}

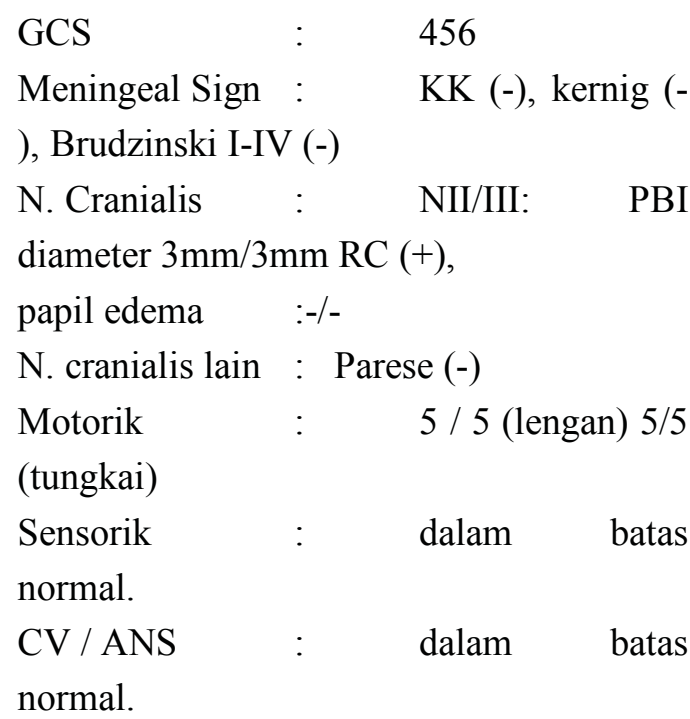

\section{Laboratorium ( 17 Maret 2013 )}

$\mathrm{dbn}$

Pemeriksaan EEG

EEG ( 24 Mei 2013)

Hasil : EEG Abnormal III (Bangun dan tidur stadium II)

- Spike Wave di regio prefrontal kanan

- $\quad$ Spike wave di regio temporal kanan

- ISA (Intermitten Slow Activity) general

EEG saat perekaman ini abnormal, mengindikasikan adanya potensial epileptogenicity di regio prefrontal kanan dan regio temporal kanan disertai ensefalopati difus derajat ringan.

\section{Radiologi}

Thorax AP

Cor dan pulmo tak tampak kelainan MRI Kepala tanpa kontras (24 mei 2013) Saat ini brain parenchym tak tampak kelainan. Tidak tampak atrofi hipokampus 
dengan volume sisi kanan:1,620 cm3 volume sisi kiri: $1,820 \mathrm{~cm} 3$.

DWI : tak tampak restricted diffusion area.

MRA: circulus wilisi patent, tak tampak malformation vascular.

\section{Tes Neurobehaviour}

- Neurobehaviour: Didapatkan gangguan pada atensi, visual memory, verbal memory, dan kategori naming

- Diagnosis tentative neurobehaviour : Saat ini didapatkan pasien dengan multidomain amnestik MCI yang dapat pula disebabkan oleh penyakit dasarnya.

Saran: Atasi penyakit dasarnya

Evaluasi pemeriksaan kognitif ulang dalam 6 bulan.

\section{Diagnosis}

\section{Diagnosis klinis :}

- Serial general tonic clonic seizure

- Behavioural changes

- Automatism

Diagnosis Topis : Korteks lobus frontotemporalis

Diagnosis Etiologis : Epilepsi simtomatik lobus temporal

$$
\text { e.c traumatic brain injury }
$$

\section{Penatalaksanaan}

- Farmakoterapi

Phenytoin kaps 3x100mg

Risperidone tab 2x0,5 mg

Asam folat tab $1 \times 1$

- Psikoterapi suportif

- Psikoedukasi keluarga

\section{PEMBAHASAN}

Epilepsi pasca trauma termasuk dalam epilepsi simtomatik. Merupakan sekuel dari trauma kepala yang paling sering terjadi, dengan insiden 5\% pada penderita dengan trauma kepala tertutup dan $50 \%$ pada penderita dengan fraktur tulang tengkorak dan jejas pada otak. ${ }^{4}$ Tipe kejang pada eplepsi pasca trauma dapat berbeda-beda bergantung pada lesi yang diakibatkan oleh trauma tersebut. Kasus ini melaporkan penderita laki-laki usia 24 tahun dengan keluhan kejang yang disertai dengan gejala psikotik. Didapatkan riwayat pasien kejang pertama kali dua bulan setelah mengalami trauma kepala yaitu pada tahun 2003. Saat itu pasien mengalami cedera otak berat tidak sadar selama 1 minggu. Dari CT scan kepala didapatkan perdarahan di otak. Sejak itu pasien mengalami kejang berulang dengan disertai keluhan yang dominan adalah marah-marah hingga pernah sampai mau membunuh orang. Dari analisis EEG menunjukkan hasil epilepsi lobus temporal. Hal ini mendukung gejala dari pasien tersebut yang menunjukkan gejala behavioral changes dan automatism yang mengarah ke psikotik epilepsi dimana pada pasien ini dengan tipe psikotik iktal. Pasien mendapatkan terapi phenytoin dan risperidone dosis standar, dan menunjukkan epilepsi telah terkontrol dengan pengobatan tersebut namun masih didapatkan kejang kemungkinan karena pasien tidak rutin minum obat. Kejadian epilepsi pada kasus ini belum sembuh hingga sepuluh tahun setelah trauma kepala.

\section{KESIMPULAN}

Pada kasus ini pasien laki-laki dengan epilepsi post trauma dengan onset 2 bulan setelah trauma kepala. Berdasarkan anamnesis dan pemeriksaan fisik dan penunjang, pasien didiagnosis epilepsi lobus frontemporal dan menunjukkan gejala menyerupai psikotik. Pasien mendapatkan pengobatan standar yaitu phenytoin dan risperidone. Kejang terkontrol namun bila tidak minum obat pasien kejang lagi. Hal ini dialami oleh pasien hingga saat kasus ini dilaporkan, yaitu sepuluh tahun post trauma. 


\section{DAFTAR PUSTAKA}

Harsono, dkk. 2011. Pedoman Tatalaksana Epilepsi. PERDOSSI. Jakarta: 1-6.

Shorvon SD. 2006. Handbook of Epilepsy Treatment. Blackwell Science. Oxford: 1-3

Ropper AH, Brown RH. Epilepsy and Other Seizure Disorders. In Ropper AH, Brown RH. Adams and Victor's Priciples of Neurology $8^{\text {th }}$ Ed. McGraw-Hill. USA: 269299

Ropper AH, Brown RH. Craniocerebral Trauma. In Ropper AH, Brown RH. Adams and Victor's Priciples of Neurology. McGrawHill. USA:762-763

Rudzinski LA, Meador KJ. 2011. Epilepsy: Five New Things. Neurology.76:S20 